\title{
MEDIA-GOVERNMENT RELATIONS: AN ANALYSIS IN STRUCTURAL FUNCTIONALIST APPROACH
}

\author{
Faiza Khalid \\ Lecturer, Mass Communication at National University of Modern Languages. \\ fkhalid@numl.edu.pk \\ Munib Ahmed \\ Assistant Professor, National University of Modern Languages \\ mahmed@numl.edu.pk \\ Rehana Munawar \\ Lecturer, Mass Communication \\ National University of Modern Languages \\ rmunawar@numl.edu.pk
}

\begin{abstract}
The present study covered two different social institutions of Pakistan's society and their effects on the media and government relations, i.e., politics and economy. The study included problems in polity and its effects on media-government relations; the economic developments and impasses and their possible consequences and effects on media-government relations. The research was qualitative quantitative in nature and descriptive method is employed to conduct the research. The findings were that the government of previous regime had a weak structure, and the functioning of the institutes was inefficient too. The relation of the government with the media, was interest based as media's practicality depends on its economy and the economy comes in the forms of advertisements. Media's effect is great and cannot be ignored; it shapes up the public opinion. The research recommends that the use of better technology should be introduced at cheaper rates for objective reporting.
\end{abstract}

Keywords: Media-government, Economy, Politics, Pakistan, Structural- Functionalist.

\section{INTRODUCTION}

Media has the status of society's central slowly but surely (Lindgren, 2021). Only available source of information in the olden days was the medium of the print, but now as the technology has advanced television and internet has taken the place. Almost everything around, us is the manipulated content of media. Media tends to control the human brain their thought from its doctrines (Graciyal \& Viswam, 2021). There are huge list of channels going on air including news, current affairs etc., and people are using internet for the purpose of news gathering as well and then discussing it in blogs and sharing it in social networks (Lee \& Min, 2021). These fashions of internet usage have given rise to the hegemony of the media in Pakistan. It is rightly demonstrated that media makes-up an agenda in people's mind by influences the 'pictures in the heads' through their messages (Wolfe et al., 2013).

Since the beginning of cable television in 2002, the news consumption attitudes of the people changed. Newspapers stimulated by the outlook and appearance style of cable news and adopted hard line and accepted style of news to enhance their declining readership. Historically, print media especially newspapers in Pakistan were considered as mature and objective in their business; currently, the observable fact of "popular and crispy" style of news is being explored for enhancing the ratings of the media outlet in the race for commercialization (Jan, 2013). The opinionated news or soft news is a common phenomenon in Pakistani print as well as electronic media.

\section{REVIEW OF LITERATURE}

Weaver and Wilhoit (2020) terms it as Media Occupations in terms of the recruitment, career paths, culture and norms of groups of media workers. Tumber (2002) explains it as enjoying a vogue, which focuses on the influence of the suppliers of the news. Lippit (2015) defines it as radical political economy, has an expansive political reach but tends in practice to focus on media ownership and 
control, and its link to power in society as well as to related issues such as functioning of markets (Sen \& Hill, 2007). Stromberg (2004) said media is concerned with public policy, and social administration of the media, often viewed in a comparative perspective (Ndlovu, 2021). Conclusively, the contents of media are taken as the shared "cultural-indicator" theory (Bauer, 2005); as a demeanor of prevailing ideologies (Parenti, 2010), in a conventional Marxist point of view (Blasch, 2021). And as an extension of the power structure, in the radical-structuralist tradition (Hallin \& Mancini, 2011). Media people like reporters, anchors, sub editors, editors and even owners do not feel any hesitation in doing subjective approach (Wimmer \& Dominick, 2013). Gehlbach and Sonin, (2014) mentioned about the attention an issue receives and the amount of concern by public about the problem. Government relations with media is to be thoroughly recheck because it resides at the boundary of journalism and the executive, two of the important organization in a modern democratic society. That line of communication is very important if the people of the country are to keep updated and informed about the workings of government and the schemes of the political system.

Chulov (2002) explained about the coverage of terrorist attacks and people attitude towards coverage, they find it impossible to turn away and hope to get information for such attacks in future. Media is also playing intricate role in shaping and controlling political opinions (McNeil, 2013). People are affected by media content by consuming it in the light of their own values and beliefs and passing on to those who follows them (Katz \& Lazarsfeld, 2017). This is how media sets an agenda in their minds by changing or shaping their attitudes and behaviors (Hovland et al., 1949). Media effects the functioning of the government by influencing the opinion leaders by its content (Flew \& Liu., 2016). Media has been termed as an influential power on society; different critics defined it in diversity. Auvinen (2012) writes it as internal processes within media organizations.

In a communication network, it is important that there should be fair amount of truth, objectivity, and transparency present. They are crucial for the good governance and informed citizenry. Almost most of the countries of the world exert control on media to hold, a hold on public opinion. In the cases where the media houses are privately owned, there are laws for them to keep them under a strict control or check and balance. Also, there are many kind of taxes, regulations and the licenses as well for media and this is how the media content is kept under pressure and the economy of them under control.

\section{Theoretical Framework}

Structural functionalism is referred by Nistbet (2017) as "without any doubt, the single most significant body of the theory in the social sciences in the present century" (Turner \& Maryanski, 1979). In the structural functionalism, the terms structural and functional need not to be used in conjunction, although they are typically conjoined. We could study the structures of the society without being concerned with their functions (or consequences) for other structures. Similarly, we could examine the functions of a variety of social processes that may not take a structural form (Abrahamson \& Fairchild, 1999). Still, the concern for both elements characterize structural functionalism. Although structural functionalism takes various forms (Wadsworth, 2008), societal functionalism is the dominant approach among sociological structural factionalists (Chojoo, 2016). The primary concern of societal functionalism is the large-scale social structures and institutions of society, their interrelationships, and their constraining effects on actors (Couldry, 2004). Structures are universal and persistent; referred as patterns of inter-relations and Functions are referred as system stability and observe consequences of a system. Structural Functionalism concentrates on the positive and negative functions of social structures (Yilmaz, 2017).

The predicaments in the institution of politics have since long been adversely affecting the functioning of other social institutions of this country. As no institution of a society can function smoothly in complete isolation, the weaknesses, and problems cruise into the other organizations too, so these problems should be seen in the context of social system (Iqbal \& Shabir, 2010). Especially in case of powerful institution of politics, the process of reaching effects to other corners is much rapid. This is what the structural functionalists claim that no activity should be explained on its own, but as a part of larger whole. Davis and Moore (1945) regarded social stratification as both universal and necessary. They argued that no society is ever unstratified, or totally classless. Stratification is, in their view, a functional necessity. All societies need such a system, and this need brings into existence a system of stratification (Kerbo, 2006). They also viewed stratification system as a structure, pointing out that stratification refers not to the individuals in the stratification system but rather to a system of 
position. They focused on how certain positions come to carry with them different degrees of prestige and not on how individuals come to occupy certain positions.

The positions that rank high within the stratification system are presumed to be those that are less pleasant to occupy but more important to the survival of the society and that require the greatest ability and talent. In addition, society must attach sufficient rewards to these positions so that enough people will seek to occupy them and the individuals who do come to occupy them will work diligently. That is, low ranking positions in the stratification system are presumed to be more pleasant and less important and to require less ability and talent. Also, society has less need to be sure that individuals occupy these positions and perform their duties with diligence. For example, despite the lower pay and prestige of garbage collectors, they may be more crucial to the survival of the society than the advertising executives. Even in cases where it could be said that one position serves a more important function for society, the greater rewards do not necessarily accrue to the more important position. Nurses may be much more important to the society than movie stars are, but nurses have far less power, prestige, and income than movie stars have. The institution of media not only helps other institutions to function properly, but problems in other institutions also effect this institution. Consequently, severe malfunctioning in other institutions hampers media to achieve its globally established adjectives.

\section{Research Questions}

Following research questions were made to carry out the research on media-government relations:

1. How the government control over media and popular public are closely associated?

2. How the media freedom and independence is a strong predictor of better media economy?

\section{METHODOLGY}

This analysis of structural functionalist approach is carried out in a descriptive analysis. According to the theorists, all institutes are interdependent on each other. The study examined all the media as a group against government. How the Gillani government-controlled media. What factors affects the government media relationships? To achieve the purpose, the key independent and dependent variables are defined, and research has been conducted in accordance with them. These are adequately discussed and described citing relevant literature while exploring the relationship between them. Among the many types of descriptive Analysis, the type used in this research is Analytical Analysis, it deals with the analysis of the past event. Events of political and Economic Importance were selected. Political and Economic indicators during the government of Gillani (2008-2012) have taken as a unit of analysis.

\section{RESULTS AND DISCUSSIONS}

As the study covers three different social institutions of Pakistan's society and their effects on the media and government relations, thus our findings would span on three sections based on our hypotheses. These three sections would include problems in policy and its effects on mediagovernment relations; the economic developments and impasses and their possible consequences and effects on media-government relations; and last but not the least the technological developments took place during the time of analysis and its effects on liberating media from the government controls.

Keeping in mind the structural functional approach on which the analysis is based, a system can only be function if the structure is strong. Weak systems are the outcome of the faulty structures. In this study, efforts have been made few newspapers and electronic channels have been studied to collect the data and it was analyzed in accordance with the hypotheses. And it was found that that media is greatly affected by the system in which it operates. The analysis would be in a shape of details of the political happening at first and then the significance of that event in the light of the above-mentioned perspectives.

During his government, the country faced sweeping changes within. The tenure of four years was marred, on and off, by some wobbly occurrences. The democracy earned with efforts proved to be a total failure. The PM of the state was disqualified by the apex court. This brought serious criticisms and questioning on the functioning of the systems. Even though Gillani tried raising the hopes for stability, while in power. The government faced thorny opposition in the face of PML-N \& PTI. Even the Army and the Judiciary was the loggers head with the government. 
During the regime, there were several major events and happenings of political importance from 2008 till 2012. Pakistan has evolved a lot. Economy, Political structure and relations with other countries are changed. Today, Pakistan's democratic system is evolving. Today's Pakistan has system in which voice of citizenry is heard and preferred. Foreign Relation with China, Middle East and Turkey are evolving in a better way.

There was a great economic recession in 2008. Because of repaid running down in economic exchange the leaders went to IMF for support. 2009 was also difficult year for Pakistan. The escalation of the US war efforts in Afghanistan had several consequences for Pakistan. The country had limited economic resources leaving less space for the development. In 2010, Pakistan was hit by a devastating amount of floods, 'one in hundred years' caused by rain falls, in areas near River Indus. Huge amount of damage was done to land, crops and physical assets. It was estimation that the loss is about 10 billion dollars and almost one fifth of the population was internally displaced. The movement was equal to the movement that occurring during Independence struggle of 1947. This migration after floods left deep impacts on Pakistan's economic, political, and social development.2011 was considered as a very busy year, but not very good. Islamabad decided to terminate all programs with the IMF, which made the situation worse than ever. Relations with the U.S. became less strong that resulted in development assistance. This raised the Oil price and GDP was declined.

For a prospering, democratic, developing, and powerful country, press-government relations are to be considered as a key aspect to the structure. Bomb Blasts, Drone attacks, High rates of Corruption, increased poverty, and inflation, decreased literacy rate, and worst law and order situation are the defining features of those of six months. A government's responsibility is to maintain the situation of law and order and to guard and provide security to its people. There is no logic of being in government if you are failed to do so. In case government fails to conserve and preserve the nation, it is free to resign and have her way home. All the incidents happened during the era created a feeling of hopelessness, anarchy, an urge for revenge and extreme hatred amongst the people. In midst of all these issues the worst part was that nobody wanted to come forward and try to improve the condition everybody thought some unseen power would emerge and solve all the problems.

In such situations where masses are not at all satisfied from the government performance, leads to terrorism, acts of violence and excessive bloodshed. Everyone gets disillusioned. The strong economy of media is a great predictor of media freedom and independence leaving less space for government to control media directly or indirectly. To explain this hypothesis, there are examples of print and electronic media, if we take the example of any media house of Pakistan, the print paper is bombarded is government advertisement and few private advertisements. The trend proves that the major share of media economy is from the government in the form of advertisements. If the rate of advertisements is high than the government pressure gets higher, and the officials of the country force them to publish as they want to 'see and hear'. The advertisements of the government are in the form of tender notices, announcements, university admissions, job opening, etc. Same is true for electronic media, but in electronic media the private sector holds the major share, if we take any example of TV channel, any program whether it is social, political, or religious is filled up with regular ad's slots. Even the live news of these days has commercial breaks. The advertiser buys the loyalties of a media house, obviously

\section{CONCLUSION}

The relation between the government and the media is very crucial. They both affect each other; there is a kind of cause-and-effect relationship between the two. Pakistan is a developing democracy from dictators entangle. The government is on the surge of development. Developing countries are like a growing child, who needs a lot of attention and care. Similar is the case with Pakistan, the country needs to be handled with care, specifically, special care. The institutes of the country should work in accordance with structures. As, explained about the theory of structural functionalism earlier, the working relation of the institutions is their inter-dependency. Media is also known as the fourth pillar of the state, because of its societal role of vital play. Publics are the followers of media. The public sees the governmental happenings from the eyes of the media. There relation is continuous like whatever happens in one institution will affect other. The Gillani government has relation with a media with regular ups and downs. Still many media houses paid the price for covering the 
democratic aspirations and opposition movements. The government performance is directly linked with the public, the weak governments like this was tries to curb the freedom. the government tried controlling the media because the popularity was going down. People view government through media's viewpoint and sometimes media reports some issues and leaves some, but at times they are equally important. They should report everything and remain objective in their approach. The media should not say all the time that the government is corrupt, even if it is corrupt, this can bring some serious and disastrous results.

\section{REFERENCES}

Abrahamson, E., \& Fairchild, G. (1999). Management fashion: Lifecycles, triggers, and collective learning processes. Administrative science quarterly, 44(4), 708-740.

Auvinen, A. M. (2012). Social media-the new power of political influence. Brussels: Suomen Toivo.

Bauer, M. (2005). "Science in the Media" as a cultural indicator: contextualizing surveys with media analysis. In Between Understanding and Trust (pp. 120-135). Routledge.

Blasch, L. (2021). Indexing authenticity in visual political (social media) communication: a metapragmatics-based analysis of two visual registers of the authentic. Multimodal Communication, 10(1), 37-53.

Chojoo, A. J. (2016). Social Transformation among Muslims in Contemporary Mauritius. In Indentured Muslims in the Diaspora (pp. 61-82). Routledge.

Chulov, M. (2002). Hacks or flacks-Media economics are blurring the lines between journalism and public relations. The Australian.

Couldry, N. (2004). Theorising media as practice. Social semiotics, 14(2), 115-132.

Davis, K., \& Moore, W. E. (1945). Some principles of stratification. American sociological review, 10(2), 242-249.

Demerath, N. J. (1949). Hovland, Lumsdaine and Sheffield. Experiments on Mass Communication (Book Review). Social Forces, 28(1), 446.

Flew, T., \& Liu, B. R. (2016). Media convergence. In Postcolonial Studies Meets Media Studies (pp. 25-42). transcript-Verlag.

Gehlbach, S., \& Sonin, K. (2014). Government control of the media. Journal of public Economics, 118, 163-171.

Graciyal, D. G., \& Viswam, D. (2021). Social Media and Emotional Well-being: Pursuit of Happiness or Pleasure. Asia Pacific Media Educator, $1326365 X 211003737$.

Hallin, D. C., \& Mancini, P. (Eds.). (2011). Comparing media systems beyond the Western world. Cambridge University Press.

Hovland, C. I., Lumsdaine, A. A., \& Sheffield, F. D. (1949). Experiments on mass communication. (studies in social psychology in world war ii). 3.

Iqbal, Z., \& Shabir, G. (2010). Press-Government Relations in Structural-Functionalist Perspective: A Case of Pakistan under General Zia (from 1977 to 1988). Pakistan Journal of Social Sciences (PJSS), 30(1).

Jan, M. (2013). Print media on coverage of political parties in pakistan: treatment of opinion pages of the 'Dawn' and 'news'. Gomal University Journal of Research, 29(1), 118-128.

Katz, E., \& Lazarsfeld, P. F. (2017). Personal influence: The part played by people in the flow of mass communications. Routledge.

Kerbo, H. R. (2006). Social stratification. Sage Publications

Lee, D. G., \& Min, I. C. (2021). Diversity of Online News Media. Digital Media, Online Activism, and Social Movements in Korea, 13.

Lindgren, S. (2021). Digital media and society. Sage.

Lippit, V. (2015). Radical political economy: Explorations in alternative economic analysis. Routledge.

McNeil, L. M. (2013). Contradictions of control: School structure and school knowledge. Routledge.

Ndlovu, M. (2021). Public Media Audiences in the Age of the Internet: Challenges and Opportunities. GSJ, 9(1).

Nisbet, R. A. (2017). The sociological tradition. Routledge.

Parenti, M. (2010). Democracy for the Few. Cengage Learning.

Sen, K., \& Hill, D. T. (2007). Media, culture and politics in Indonesia. Equinox Publishing. 
Strömberg, D. (2004). Mass media competition, political competition, and public policy. The Review of Economic Studies, 71(1), 265-284.

Tumber, H. (2002). Sources, the Media and the Reporting of Conflict. In Media and conflict: Framing issues, making policy, shaping opinions (pp. 135-151). Brill Nijhoff.

Turner, J. H., \& Maryanski, A. (1979). Functionalism. Menlo Park, CA: Benjamin/Cummings Publishing Company.

Wadsworth, Y. (2008). Is it safe to talk about systems again yet?. Systemic Practice and Action Research, 21(2), 153-170.

Weaver, D. H., \& Wilhoit, G. C. (2020). The American journalist in the 1990s: US news people at the end of an era. Routledge.

Wimmer, R. D., \& Dominick, J. R. (2013). Mass media research. Cengage learning.

Wolfe, M., Jones, B. D., \& Baumgartner, F. R. (2013). A failure to communicate: Agenda setting in media and policy studies. Political Communication, 30(2), 175-192.

Yilmaz, S. R. (2017). The role of social media activism in new social movements: Opportunities and limitations. International Journal of Social Inquiry, 10(1), 141-164. 